\title{
AROMATIC PLANTS FROM VIETNAM, SOURCES OF NATURAL PRODUCTS FOR INDUSTRY
}

\author{
TRAN MINH HOI, TRAN HUY THAI \\ Institute of Ecology and biological Resources (IEBR) \\ ANGE BIGHELLI, JOSEPH CASANOVA \\ The Corsica Paul-Paoli University, French
}

\begin{abstract}
: aromatic plants produce by vapour distillation or other processes essential oils which are products with high commercial value used in the natural product industries such flavour and fragrance, perfumes and cosmetics industries as well as pharmaceutical industry. The aim of this study was to characterise some aromatic plants from Vietnam through the chemical composition of their essential oils. We got interested in essential oils which contained a main component with high to ultra high content, susceptible to find an industrial use. For this study, a dozen of plants have been selected. The composition of their essential oils will be compared with those of the same plants, reported in the literature, from Vietnamese origin or from other countries.

Key words: Vietnam, Aromatic Plants, Essential oils, Agastache rugosa (Fisch. et Mey.) Kuntze, Blumea myriocephala DC., Cinnamomum cassia Presl., Coleus aromaticus Benth., Cymbopogon martinii (Roxb.) Wats., Eucalyptus citriodora Hook., Illicium verum Hook. f., Kaempferia galanga L., Ocimum basilicum L. var. pilosum (Willd.) Benth., Ocimum gratissimum L., Michelia balansae (DC.) Dandy, Litsea cubeba (Lour.) Pers., anethole, carvacrol, (E)-cinnanlaldehyde, Ethyl p-methoxy-(E)-cinnamate, citronellal, eugenol, estragole, geraniol, linalool, thymyl methyl oxide, safrole.
\end{abstract}

Essential oils are obtained by water distillation or vapour distillation of the whole plant or part of the plant (aerial parts, leaves, flowers, fruits, seeds, stems, wood, roots). They are, in general, complexes mixtures of several tens and sometimes more than one hundred components, present in variable proportions. The components are, most of the time, terpene hydrocarbons or oxygenated terpenes containing 10,15 and scarcely 20 atoms of carbon (mono, sesqui and diterpenes), bearing very diverse skeleton, acyclic, cyclic, bicyclic, polycyclic (eventually bridged) and functionalities, olefins, alcohols, aldehydes, ketones et esters. Phenylpropanoids may be observed as well as linear non terpenic compounds. However, a few essential oils contain a main component which is by far the most important and could constitute an industrial source of this natural compound. Such essential oils, with high commercial value, could be of interest for natural product industries such flavour and fragrance, perfume and cosmetic industries as well as pharmaceutical industry.

The world annual production of essential oils was estimated to 45,000 tons which represented in the early nineteen's a value of 700 millions of US dollars. The essential oils, which are obtained without the use of solvent or reactant are free of chemical pollution. Moreover, in most cases, the plant produces a single enantiomer of a molecule, enantiomer which possesses specific olfactory or pharmaceutical properties.

This study was achieved in the course of an important work concerning the characterization of aromatic plants from Vietnam through the chemical composition of their essential oils. We got interested in essential oils which contained a main component with high to ultra high content, susceptible to find an industrial use. For this study, a dozen of plants have been selected. The composition of their essential oils will be compared with those of the same plants, reported in the literature from Vietnamese origin or from other countries. 


\section{EXPERIMENTAL METHODS}

\section{Analytical GC}

GC analysis was carried out with a PerkinElmer Autosystem apparatus equipped with two flame ionisation detectors, and fused-silica capillary columns $(50 \mathrm{~m} \times 0.22 \mathrm{~mm}$ i.d., film thickness $0.25 \mu \mathrm{m}$ ), BP-1 (polydimethylsiloxane) and BP-20 (polyethyleneglycol). The oven temperature was programmed from $60 \square \mathrm{C}$ to $220 \square \mathrm{C}$ at $2 \square \mathrm{C} / \mathrm{min}$ and then held isothermal (20 min); Detector temperature: $250 \square \mathrm{C}$; Injector temperature: $250 \square \mathrm{C}$ (injection mode: split 1/60). Carrier gas: helium $(0.8 \mathrm{~mL} / \mathrm{min})$. Injected volume: $0.5 \mu \mathrm{l}$ of a solution of $50 \mu \mathrm{l}$ of the oil diluted in $350 \mu \mathrm{l}$ of $\mathrm{CCl}_{4}$ acquired oven the mass range 35-350 Da. Split: 1/80. Other GC conditions were the same as described under GC. GC-MS analyses were carried out on both columns.

\section{2. ${ }^{13} \mathrm{C}$-NMR Analysis}

All NMR spectra were recorded on a Bruker AC 200 Fourier transform spectrometer operating at $50.323 \mathrm{MHz}$ for ${ }^{13} \mathrm{C}$, equipped with a $10 \mathrm{~mm}$ [or $5 \mathrm{~mm}$ ] probe, in $\mathrm{CDCl}_{3}$, with all shifts referred to internal TMS. ${ }^{13} \mathrm{C}-\mathrm{NMR}$ spectra were recorded with the following parameters: pulse width (PW), $5 \mu \mathrm{s}$ [or $3 \mu \mathrm{s}$ ] (flip angle $45 \square$ ); acquisition time, $1.3 \mathrm{~s}$ for $32 \mathrm{~K}$ data table with a spectral width (SW) of 12500 $\mathrm{Hz}$ (250 ppm); CPD mode decoupling; digital resolution $0.763 \mathrm{~Hz} / \mathrm{pt}$.

In a typical procedure, $200 \mathrm{mg}$ [or $70 \mathrm{mg}$ ] of the essential oil were diluted in $2 \mathrm{ml}$ [or $0.5 \mathrm{ml}$ ] of $\mathrm{CDCl}_{3}$. The number of accumulated scans was 3000 - 6000 for each sample, depending on the quantity of the oil available. Exponential line broadening multiplication $(\mathrm{LB}=1 \mathrm{~Hz})$ of the free induction decay (FID) was applied before Fourier transformation.

\section{Identification of components}

Identification of the individual components was based: (i) on comparison of their GC retention indices (RI) on apolar and polar columns, determined relative to the retention times of a series of $n$-alkanes with linear interpolation ('Target Compounds' software of Perkin-Elmer), with those of authentic compounds or literature data, (ii) on computer matching with a laboratory made mass spectral library and commercial libraries and comparison of spectra with literature data, (iii) on comparison of the signals in the ${ }^{13} \mathrm{C}$-NMR spectra of the selected samples with those of reference spectra compiled in the laboratory spectral library, with the help of a laboratory-made software $[15,16]$.

\section{RESULTS AND DISCUSSION}

Among the numerous plant of Vietnamese origin we have investigated within a research program sponsored by the French Foreign Ministry and the Collectivité Territoriale de Corse [11], we have selected a dozen of aromatic plants which produce an essential oil dominated by a single component. The content of that compound in the oil may be high, very high or extremely high and consequently, the essential oil could be a source of this compound for the industry of natural products.

The essential oils of six aromatic plants contained mainly a component bearing the phenylpropanoid framework. This compound is: Anethol in the oil from star anis, Illicium verum Hook. f.; Estragole in the oil from Agastache rugosa (Fisch. et Mey.) Kuntze; Eugenol in the oil from Ocimum gratissimum L.; safrole in the oil from Michelia balansae (DC.) Dandy; (E)cinnamaldehyde in the oil from Cinnamomum cassia (Nees) Nees et Eberh; (E)-ethyl cinnamate and (E) para-methoxy-ethyl cinnamate in the oil from Kaempferia galanga $\mathrm{L}$.

The six other essential oils are dominated by aromatic or acyclic monoterpenes; they are: Carvacrol in the essential oil from Coleus aromaticus Benth.; Thymyl methyl oxide in the oil from Blumea myriocephala DC.; Linalool in the oil from Ocimum basilicum L. var. pilosum (Willd.) Benth; Citronellal in the oil from Eucalyptus citriodora Hook.; Geraniol in the oil from Cymbopogon martinii (Roxb.) Wats.; Citral (geranial and neral mixture) in the oil from Litsea cubeba (Lour.) Pers.

Although, in the course of this program, we have analysed several samples of essential oil extracted from the investigated plants, we only report in the tables 1 and 2 , the chemical composition one sample. The chemical structures of the main compounds are reported in the figure 1. 
Chemical composition of phenylpropanoid rich oils from Vietnam (samples 1-6)

\begin{tabular}{|l|c|c|c|c|c|c|c|}
\hline \multicolumn{1}{|c|}{ Components } & RI & $\mathbf{1}$ & $\mathbf{2}$ & $\mathbf{3}$ & $\mathbf{4}$ & $\mathbf{5}$ & $\mathbf{6}$ \\
\hline$\alpha$-pinene & 931 & - & - & - & 1.4 & - & - \\
\hline$\beta$-pinene & 972 & - & - & - & 3.0 & - & - \\
\hline Limonene & 1021 & 2.5 & 1.8 & - & 4.8 & - & - \\
\hline$($ E)- $\beta$-ocimene & 1024 & - & - & - & 1.4 & - & - \\
\hline Linalool & 1081 & - & - & - & 1.4 & - & - \\
\hline Estragole & $\mathbf{1 1 2 4}$ & - & $\mathbf{9 6 . 2}$ & - & - & - & - \\
\hline Borneol & 1149 & - & - & - & - & 0.4 & 3.1 \\
\hline$($ E)-cinnamaldehyde & $\mathbf{1 2 3 6}$ & - & - & - & - & $\mathbf{9 2 . 4}$ & - \\
\hline Safrole & $\mathbf{1 2 6 2}$ & - & - & - & $\mathbf{8 4 . 5}$ & - & - \\
\hline$($ E)-anethole & $\mathbf{1 2 6 8}$ & $\mathbf{9 3 . 1}$ & - & - & - & - & - \\
\hline Cinnamyl alcohol & 1270 & - & - & - & - & 0.4 & - \\
\hline Eugenol & $\mathbf{1 3 3 7}$ & - & - & $\mathbf{8 2 . 7}$ & - & - & - \\
\hline$\alpha$-copaene & 1379 & - & - & 1.7 & - & - & - \\
\hline Coumarin & 1388 & - & - & - & - & 0.7 & - \\
\hline Cinnamyl acetate & 1409 & - & - & - & - & 0.6 & - \\
\hline E)-trans-caryophyllene & 1424 & - & - & 3.8 & - & - & - \\
\hline E)-ethyl cinnamate & $\mathbf{1 4 3 4}$ & - & - & - & - & - & $\mathbf{2 6 . 8}$ \\
\hline Germacrene-D & 1480 & - & - & 1.1 & - & - & - \\
\hline$\delta$-cadinene & 1516 & - & - & 1.5 & - & - & - \\
\hline E)-ethyl p-methoxy cinnamate & $\mathbf{1 7 1 9}$ & - & - & - & - & - & $\mathbf{6 4 . 1}$ \\
\hline
\end{tabular}

Note: order of elution, retention indices (RI) and percentages are given on apolar column (BP-1). Investigated plants: 1. Illicium verum; 2. Agastache rugosa; 3. Ocimum gratissimum; 4. Michelia balansae; 5. Cinnamomum cassia; 6. Kaempferia galanga.

Table 2

Chemical composition of monoterpenoid rich oils from Vietnam (samples 7-12)

\begin{tabular}{|l|c|c|c|c|c|c|c|}
\hline \multicolumn{1}{|c|}{ Components } & RI & $\mathbf{7}$ & $\mathbf{8}$ & $\mathbf{9}$ & $\mathbf{1 0}$ & $\mathbf{1 1}$ & $\mathbf{1 2}$ \\
\hline p-cymene & 1011 & 2.7 & 0.8 & - & - & - & - \\
\hline Limonene & 1021 & - & - & - & - & 9.5 & - \\
\hline$\gamma$-terpinene & 1048 & 2.3 & - & - & - & - & - \\
\hline Linalool & $\mathbf{1 0 8 1}$ & - & - & $\mathbf{7 9 . 0}$ & - & 2.9 & 3.4 \\
\hline Citronellal & $\mathbf{1 1 3 6}$ & - & - & - & $\mathbf{7 8 . 2}$ & 1.6 & - \\
\hline Isopulegol & 1136 & - & - & - & 5.6 & - & - \\
\hline Neoisopulegol & 1146 & - & - & - & 3.2 & - & - \\
\hline Terpinen-4-ol & 1160 & 1.3 & - & - & & & \\
\hline Citronellol & 1210 & - & - & - & 4.9 & - & - \\
\hline Nerol & 1211 & - & - & - & - & 0.9 & - \\
\hline Thymyl methyl oxide & $\mathbf{1 2 1 4}$ & - & $\mathbf{9 7 . 7}$ & & & & \\
\hline Neral & $\mathbf{1 2 1 4}$ & - & - & - & - & $\mathbf{2 6 . 8}$ & 1.7 \\
\hline Geraniol & $\mathbf{1 2 3 2}$ & - & - & - & - & 1.1 & $\mathbf{6 9 . 2}$ \\
\hline Geranial & $\mathbf{1 2 3 7}$ & & & & & $\mathbf{4 4 . 1}$ & 4.4 \\
\hline Carvacrol & $\mathbf{1 2 7 8}$ & $\mathbf{8 2 . 7}$ & - & - & - & - & - \\
\hline Citronellyl acetate & 1334 & - & - & - & 0.8 & - & - \\
\hline Eugenol & 1337 & 1.3 & - & - & - & - & - \\
\hline
\end{tabular}




\begin{tabular}{|l|c|c|c|c|c|c|c|}
\hline Geranyl acetate & 1357 & - & - & - & - & - & 12.1 \\
\hline Aristolene & 1420 & - & - & - & - & 1.9 & - \\
\hline$($ E)-trans-caryophyllene & 1424 & 2.6 & - & 2.9 & - & - & - \\
\hline Trans- $\alpha$-bergamotene & 1432 & 1.9 & - & 2.2 & - & - & - \\
\hline$\alpha$-humulene & 1456 & 0.7 & - & - & - & - & - \\
\hline$\beta$-selinene & 1485 & & - & 2.5 & - & - & - \\
\hline$\alpha$-selinene & 1494 & - & & $2.2-$ & - & - & - \\
\hline Caryophyllene oxide & 1579 & 1.1 & - & - & - & - & 1.1 \\
\hline
\end{tabular}

Note: order of elution, retention indices (RI) and percentages are given on apolar column (BP-1). Investigated plants: 7: Coleus aromaticus, 8: Blumea myriocephala, 9: Ocimum basilicum var. pilosum, 10: Eucalyptus citriodora, 11: Litsea cubeba, 12: Cymbopogon martinii.

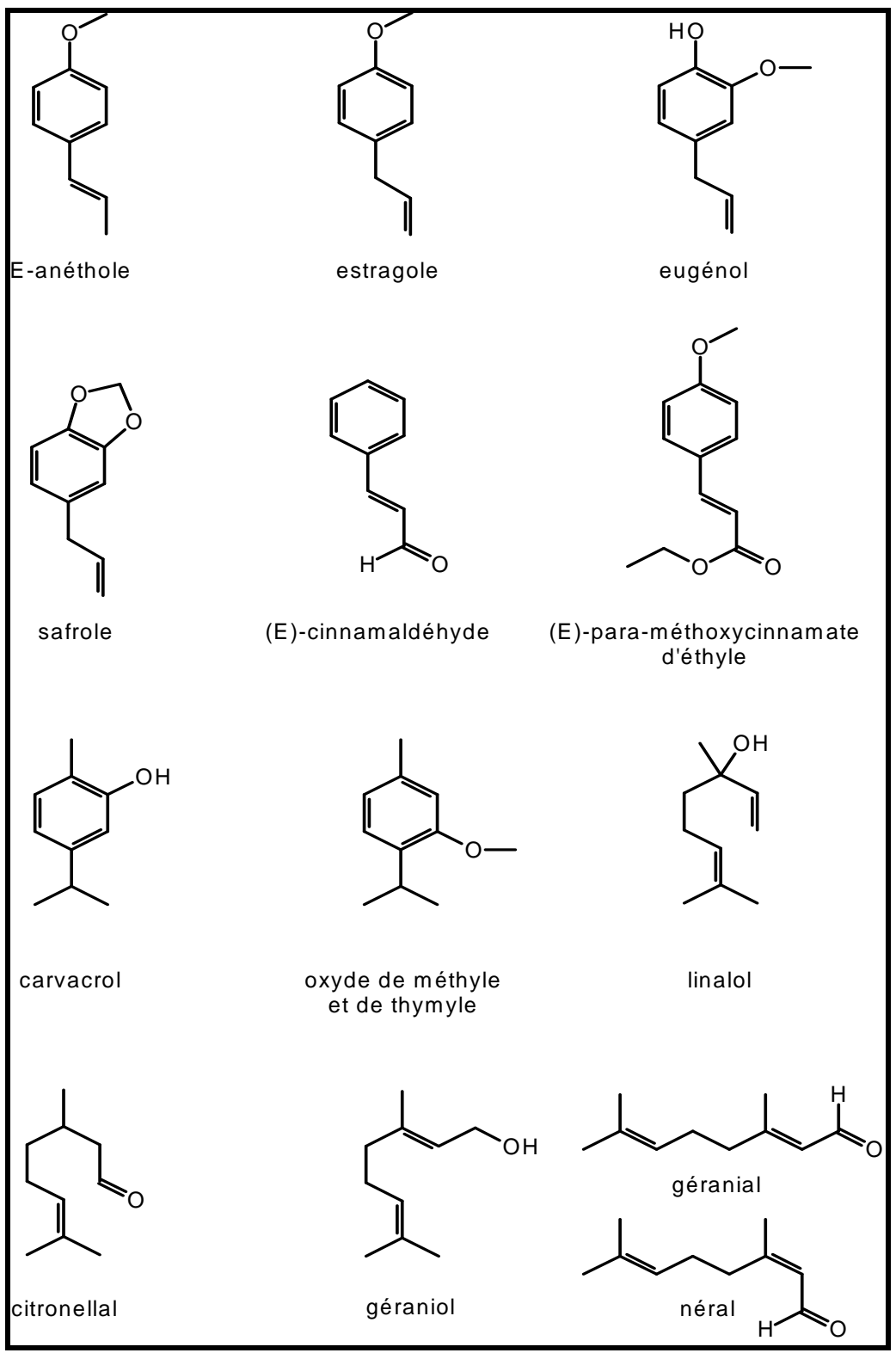

Figure 1. Structure of the major components identified in essential oils from Vietnam 
1. Illicium verum Hook. f. (star anis) essential oil, source of $(E)$-anethole

Illicium verum (star anis) is widely cultivated in Vietnam and used as medicinal plant [12a]. The analysed sample contained $93 \%$ of (E)-anethole [synonym (E)-1-methoxy-4-(1propenyl)-benzene; (E)-4-(1-propenyl)-anisole] and $2.5 \%$ of limonene, the single one other compound present at noticeable content. Anethole is widely used in the production of fragrances and it is particularly present in soaps and in cleaning materials. The (E) isomer is rather used as floral base in the products intended for fine perfumery. Essential oil of Illicium verum possess an interesting antimicrobial activity, specially induced by the presence of anethole. The content of (E)anethole in this sample is very high, compared to those reported in the literature $[1,2]$ and reviewed by Lawrence [7]: 71-78\% for the oils from China in which the major compound is present with another oxygenated compound as anisaldehyde, estragole or foeniculine; $88 \%$ for samples from unspecified origin.

\section{Agastache rugosa (Fisch. et Mey.) Kuntze essential oil, source of estragole}

The investigated sample contained $96 \%$ of estragole [synonym $=1$-methoxy-4-allylbenzene, 4-allylanisole, methylchavicol]. It possess an herbaceous odour slightly similar to that of anis and it is used for the preparation of synthetic oils such as estragon oil. The chemical composition of this sample is close to that reported by Dung et al in which the content of estragole varied from 76 to $92 \%$, according to the part of the plant. It seems that the chemical composition of the essential oil of Agastache rugosa from Vietnam is more homogeneous than that reported by Fujita (estragole and methyleugenol: $83-92 \%$ ) or by Svoboda et al (estragole and menthone and/or isomenthone, plant cultivated in Scotland) and is quite different to that reported by Lawrence (isomenthone $10-57 \%$, pulegone $9-52 \%$, plant cultivated in North Carolina).

\section{Ocimum gratissimum L. essential oil, source of eugenol}

The analysed sample is characterised by the predominance of eugenol (83\%) [synonym: 2methoxy-4-allylphenol, 1-hydroxy-2-methoxy4-allylbenzene]. We noticed that the other components present at a content which allows their identification by ${ }^{13} \mathrm{C}-\mathrm{NMR}$ are all sesquiterpenes: (E)-caryophyllene, $\alpha$-copaene, $\delta$-cadinene and D-germacrene. Eugenol is widely used in pharmacy, perfumery, cosmetic and agribusiness (meats, sausages and sauces) due to its strange and pleasant smell of clove. The essential oil of Ocimum gratissimum, that possess an important antibacterial activity, was widely studied and several chemical compositions have been reported. Concerning the two more important compositions, one is dominated by eugenol and the other by thymol $[1,2]$. Our sample, that belongs to the first composition, is similar to that reported by Dung et al (eugenol, 74\%), also from Vietnam. It is also similar to the eugenol rich oils (32-90\%) reported by Lawrence from China, USSR, India, Madagascar, Taiwan, North America and from unspecified origin. However, the chemical composition of our sample differed from those of the oils from Rwanda, Cuba, Bangladesh, Benin and Sao-Tome and Principe, characterised by a high content of thymol (35-60\%). Otherwise, our sample is also different to the other samples reported in the literature with unusual chemical compositions: 2 samples from Brazil, respectively dominated by methyleugenol/eugenol and by p-cymene/(E)- $\beta$ farnesene/thymol; one sample characterised by $\beta$-caryophyllene/eugenol/ $\beta$-elemene (unspecified origin); some compositions dominated by linalool, citral or ethyl cinnamate have been also reported.

\section{Michelia balansae (DC.) Dandy essential oil, source of safrole}

We analysed a sample of essential oil obtained from the aerial parts of Michelia balansae (DC.) Dandy (Magnoliaceae). Six compounds, amounting for $97 \%$ of the global composition, were identified. Safrole [synonym 4-allyl-1,2-methylenedioxybenzene, 3,4methylenedioxyallylbenzene] is the major component $(85 \%)$. The five other important components (1.4 - 4.8\% each) are all monoterpenes. Safrole possesses a smell similar 
to that of sassafras and it is widely used as flavour (drinks, chewing-gums), in pharmaceuticals (tooth pastes) and in the manufacture of detergents (soaps). The chemical composition of our sample is similar to those reported by Dung et al for essential oils obtained from seeds and pulp of fruits from Vietnam. The last oils contained also safrole (73 and $70 \%$, respectively) together with methyleugenol (19 and 24\%, respectively) not present in our sample at a content sufficiently high to be identified by ${ }^{13} \mathrm{C}-\mathrm{NMR}$. However, the investigated sample differed drastically from those of trunk (camphor 24\%), bark (camphor $16 \%$, safrole $15 \%, \beta$-caryophyllene $16.9 \%$ and elemicine 14\%) and leaves (elemicine $46.3 \%$ and $\beta$-caryophyllene $16.9 \%$ ) which exhibited a higher content of terpenes.

5. Cinnamomum cassia (Nees) Nees et Eberh. essential oil, source of (E)cinnamaldehyde

Cinnamomum cassia (Nees) Nees et Eberh. was introduced since a long time in Vietnam were it is cultivated in the mountainous regions particularly for its cork which can be harvested when the tree is $8-10$ years old (12c). The cork oil contains $60-75 \%$ (E)-cinnamaldehyde [synonym $=(\mathrm{E})-3$-phenylpropenal] [12c]. In the investigated samples of this study, the content of (E)-cinnamaldehyde reached up to $90 \%$ of the composition of the oils extracted from cork, stems and trunk of Cinnamomum cassia. In the sample whose composition is reported in the table 1 , we noted the occurrence, obviously at low level of cinnamyl alcohol an $d$ the corresponding acetate, as well as borneol, a monoterpene alcohol, coumarin, a compound scarcely found in essential oils and which may result from the cyclisation of 3-phenylprop-2enoic acid. Due to its strong spiced odour, Ecinnamaldehyde is used as a precious ingredient in perfumery. The composition of the investigated sample is close to that of the essential oil, also of Vietnamese origin, reported by Nguyen Thi Tam et al.. Such a composition dominated by E-cinnamaldehyde is extensively reported in the literature $[1,2]$ and reviewed by Lawrence [6]: although E-cinnamaldehyde is always the main component, its content varied from 55 to $97 \%$ of the whole composition of the essential oils, depending of the part of the plant hydrodistilled (leaves, branches or cork) as well as the origin of the plant. E-cinnamaldehyde is associated to benzaldehyde, coumarin, 2methoxycinnamaldehyde or sometimes, sesquiterpenes.

\section{Kaempferia galanga L. essential oil, source of (E)- Ethyl para- Ethoxycinnamate and (E)- Ethyl cinnamate}

Kaempferia galanga (Zingiberaceae) is a tropical species scarcely found in the wild in Vietnam [12d]. The plant is cultivated in India an in Vietnam and is used as spice. In the folk medicine, the plant is known to facilitate digestion [12d]. The essential oil is extracted from rhizomes. The investigated sample was characterised by the occurrence of Ethyl (E)cinnamate and overall its para-methoxylated derivative, Ethyl (E)-para-methoxycinnamate, the two compounds accounting for 37 et $64 \%$ of the composition of the essential oil, respectively. The chemical composition of that sample is in agreement with those reported in the literature $[1,10]$.

7. Coleus aromaticus Benth. essential oil, source of carvacrol

Coleus aromaticus Benth. (synonyms = Coleus amboinicus Lour., Plectranthus amboinicus Lour.) is cultivated in Vietnam since a long time, in the central part of the country. Leaves contain an essential oil which has an antibacterial activity [7e]. Carvacrol [2methyl-5-isopropylphenol, 2-hydroxy-paracymene] is reported as the main component of Coleus aromaticus oil obtained by hydrodistillation $[1,2]$. The investigated samples presented an extremely high content of carvacrol $(83 \%)$. Beside the main component and few monoterpenes, we observed the occurrence of several olefinic sesquiterpenes, (E)- $\beta$-caryophyllene, trans- $\alpha$-bergamotene, $\alpha$ humulene. Like thymol, carvacrol possesses antiseptic and germicide properties. For comparison purposes, the sample of Vietnamese origin, analysed by Dung et al. contained only $40 \%$ of carvacrol. The content in carvacrol of the investigated sample is higher than that of several samples of different origins and reported 
in the literature: Martinique (72\%), India (60\%), Cuba (51\%), Mauritius Island (40\%) and Pakistan (40\%). Conversely, the composition of our sample differed drastically from that of samples containing $41 \%$ et $80 \%$ de thymol respectively, one from Pakistan, the other of undetermined origin as well as from that of a sample from Seychelles which was dominated by p-cymenene ( $46 \%)$.

\section{Blumea myriocephala DC. essential oil, source of thymyl mehyl oxide}

The investigated sample was characterised by the pre-eminence of thymyl methyl oxide which accounted for $98 \%$ of the chemical composition of B. myriocephala leaf oil from Vietnam. The composition is close to that reported by Dung et al. for an essential oil extracted from fresh leaves and stems of $B$. lanceolaria also of Vietnamese origin, (thymyl methyl oxide about $95 \%$ of the composition). Conversely, the two compositions are drastically different from that reported for an oil of B. myriocephala of Indian origin characterised by the occurrence of chrysanthenone (37\%), a monoterpene ketone bearing the bridged bicyclic skeleton of pinane, and by several others linear non terpenic compounds.

\section{Ocimum basilicum var. pilosum (Willd.) Benth. essential oil, source of linalool}

Ocimum basilicum var. pilosum is used for flavouring foods as well as in cosmetics and fragrances industries $[1,2]$. The essential is obtained by water distillation of the aerial parts or only of the flowers. Several studies on the chemical composition of $O$. basilicum essential oils have been reported and reviewed by Lawrence [9]. Among them, the two most common were characterized by the preeminence of methylchavicol (La Reunion, Comoros, Seychelles and Madagascar islands, India, Thailand, Cuba, Nigeria) [9], Vietnam [9], or by the presence of linalool (France, Italy, Spain, Hungaria, Poland, Turkey, USA and Africa) [9]. Two other chemical compositions of basil oil were reported in the literature, the major components being methyl cinnamate (Fiji islands, Morocco) and eugenol (accompanied by linalool) [9], respectively. Finally, atypical chemical compositions exhibiting dihydrotagetone, menthol and menthone as major components were described in the literature [9]. Several of these compositions were found in the essential oils extracted from plants of $O$. basilicum, of Comorian origin and cultivated in Vietnam and which have been analysed in our laboratories [13]. The investigated sample was characterized by the presence of a high content of linalool [3,7dimethylocta-1,6-dien-3-ol] (79\%) and 4 hydrocarbon sesquiterpenes: (E)- $\beta$ caryophyllene $(2.9 \%)$, trans- $\alpha$-bergamotene $(2.2 \%)$ and the two isomers $\beta$ - and $\alpha$-selinenes (which amounted respectively for 2.5 and $2.2 \%$ ). Because of its pleasant odour of lily of the valley, linalool is one of the most important compounds for industries of perfumery, cosmetics and detergents.

\section{Eucalyptus citriodora Hook. essential oil, source of citronellal}

The Vietnamese essential oil of Eucalyptus citriodora exhibited a high content $(78 \%)$ of citronellal [3,7-dimethyloct-6-en-1-al], a monoterpene aldehyde which exhibited an odour of Melissa appreciated in the perfume and also in the detergent industries. Moreover, citronellal can be used like the starting material for the synthesis of menthol, an interesting compound for perfumery and food industries. The investigated sample of E. Citriodora, contained also citronellol and its acetate as well as two isomers of isopulegol. The chemical composition of the Vietnamese essential oil is as usual and its content of citronellal was fair in comparison with those reported in the literature [7]: Argentina (56\%), Benign (65\%), China (67\%), Cuba (75\%), Brazil (76\%), Spain (80\%), Kenya (88\%) and India (90\%). Conversely, our sample differed from the citronellol rich oil (56$70 \%$ ) from Colombia and the 1,8-cineole rich oil (55\%) of Rwanda.

\section{Litsea cubeba (Lour.) Pers., source of citral}

In Vietnam, Litsea cubeba (Lour.) Pers. (synonym: Litsea citrata Blume) is abundant in the hills and mountains at an altitude between 500 and $1000 \mathrm{~m}$. The essential oil which was extracted from the fruit belongs to the 10 most important oils in terms of commercial value. 
Citral and methylheptenone, the two major components of the oil, amounted respectively for $70 \%$ and $20 \%$ approximately [12e]. The Vietnamese essential oil, obtained by water distillation of fruits of L. cubeba, was characterized by the presence of the high content $(70 \%)$ of citral (mixture of geranial [3,7dimethyl-octa-2(E),6-dienal] and neral [3,7dimethyl-octa-2(Z),6-dienal]). Citral was used as ingredient in the lemon- and orange-flavoured non natural perfumes, but also in the detergent and cosmetic industries. In addition to the two isomer aldehydes, the essential oil exhibited the presence of several monoterpenes and one sesquiterpene: aristolene (1.9\%), which was not yet found in the essential oils from Vietnam. The chemical composition of our sample was close to that of other samples coming from various Vietnamese provinces [14] in which epoxygeranial and epoxyneral were identified as probably secondary products of distillation process. Several studies on the chemical composition of L. cubeba fruit oil have been reported in the literatures $[1,2]$ and reviewed by Lawrence and Choudhury et al. Its appears, that the chemical composition of the investigated oil was intermediate between that of the Indian sample in which citral amounted for more than $90 \%$ and those of the oils from China and Thailand where citral (50-63\%) was identified in presence of an appreciable amount of limonene (23-25\%). Conversely, it differs drastically from the the chemical composition of an essential oil from India in which citronellal $(45-77 \%)$ was the major compound. The leaf essential oil from Vietnam was investigated and it was characterized by an chemical variability [3].

\section{Cymbopogon martinii (Roxb.) Wats., geraniol rich}

Cymbopogon martinii (Roxb.) Wats. (Poaceae) was introduced recently in Vietnam (1982) [12e]. Geraniol [3,7-dimethylocta2(E),6-dien-1-ol] was the major compound $(69 \%)$ of the essential oil of palmarosa obtained from $C$. martini, the second compound in importance being its acetate. Linalool, geranial and neral were present at low contents. Like linalool, geraniol is an invaluable ingredient used and appreciated in industries of perfumery, cosmetics and detergents for its pleasant odour of rose. The chemical composition of the investigated Vietnamese oil was close to those obtained from Vietnam and reported by Dung et al. in which geraniol amounted for $72 \%$. The content of geraniol in our samples was completely acceptable in comparison of those from various origins reported in the literatures $[1,2]$ and reviewed by Lawrence [8]: 92 and $80 \%$ in Brazil, $84 \%$ in Madagascar, $76 \%$ in India, $60 \%$ in Guatemala and from 50 to $80 \%$ for samples of which the origin was not specified.

\section{CONCLUSION}

In the course of the French - Vietnamese program (Coopération décentralisée Région Corse - Provinces du Nord - Vietnam), our two groups worked on more of fifty aromatic plants from Vietnam: selection of plants, sampling, harvest, extraction of essential oils, analysis by several complementary techniques, detailed study with or without fractionation on column chromatography, chemical variability $\square$. Among these plants, we selected a dozen which produced an essential oil dominated by a single component. The essential oil may be considered as a potential source of that natural compound. We have compared our results with those reported in the literature from Vietnam or from other origin.

Acknowledgements: the authors are indebted to the Collectivite territoriale de Corse, the French Foreign Ministry of French and the Caisse des Dépôts et Consignations for financial support (Programme de coopération décentralisée Corse - Vietnam) and the Société Montier (Ghisonaccia Corsica) for a research grant and to the Program of basic researches, Vietnam for financial support.

\section{REFERENCES}

1. Arctander S., 1960: Perfume and Flavor Materials of Natural Origin, Elizabeth NJ, U. S. A.

2. Bauer K., Garbe D. and Surburg H., 1990: Common fragrance and flavor materials, VCH Publishers, New York.

3. Bighelli A. et al., 2005: J. Essent. Oil Res., in press. 
4. Chalchat J. C. et al., 1997: Rivista Italiana EPPOS, numero speciale: 644.

5. Dung N. X. et al., 1996: J. Essent. Oil Res., 8: $135-138$

6. Lawrence B., 1995: Essential Oils, Cinnamomum cassia, 1992-94, 163; 1978, 1, 13; 1976-1977, 10, 22, Allured Publishing Corporation, Carol Stream.

7. Lawrence B., 2003: Perfum. \& Flavor., 28(6): 56-75.

8. Lawrence B., 1981-87, 1988: Essential Oils, Cymbopogon martinii: 92, 81; 237.

9. Lawrence B., 1995, 1998: Perfum. \& Flavor., 20: 35- 37; 23(6): 35.

10. Luger P., Weber M., Dung N. X. and Tuyet T. B., 1995: J. Applied Crystallographica, C51.
11. Muselli A., Tran Minh Hoi, Luu Dam Cu, La Dinh Moi, Bessiere J.-M., Bighelli A., Casanova J., 1999: Flavour Fragr. J., 14: 41-44.

12. National Institute of Materia Medica, 1999: a) vol 2: 34-38; b) vol 2: 146-148; c) vol 1: 193-200; d) vol 2: 42-46; e) vol 2: 6265; f) vol 1: 271-275. Selected Medicinal Plants in Vietnam, Science \& Technology Publishing house, Hanoi, Vietnam.

13. Nguyen Thi Phuong Thao et al., 1999: Revue pharmaceutique, 1: 14-20.

14. Nguyen Thi Tam et al., 2005: Revue Chimique, in Press.

15. Tomi F et al., 1995: J. Magn. Reson. Anal., 1: 25-32.

16. Tomi F., Casanova J., 2000 : Ann. Fals Exp. Chim., 93(952): 313-330.

\title{
CÂY CÓ TINH DẦU CỦA VIÊT NAM, NGUỒN SẢN PHẨM THIÊN NHIÊN DÙNG CHO CÔNG NGHIỆP
}

TRẦN MINH HỢI, TRẦN HUY THÁI, ANGE BIGHELLI, JOSEPH CASANOVA

\begin{abstract}
TÓM TÁ́T
Tinh dầu thu được bằng phương pháp chưng cất lôi cuốn hơi nước và một số phương pháp khác là những sản phẩm có giá trị thương mại cao dùng trong công nghiệp hương liệu, nước hoa và mỹ phẩm. Mục tiêu của công trình này là đánh giá một số cây có tinh dầu của Việt Nam thông qua thành phần hoá học trong tinh dâu.

Chúng tôi rất quan tâm những loại tinh dầu có chứa một hợp chất chính với hàm lượng từ cao đến cực cao có thể sử dụng trong các ngành công nghiệp. Trong bài báo này, chúng tôi đã lựa chọn 12 cây có tinh dầu có tiềm năng phát triển lớn ở Việt Nam để nghiên cứu. Thành phần hoá học trong tinh dầu của chúng được so sánh với cùng một loài đã được công bố trong các tài liệu ở Việt Nam cũng như các nước khác.
\end{abstract}

Ngày nhận bài: 8-2-2007 